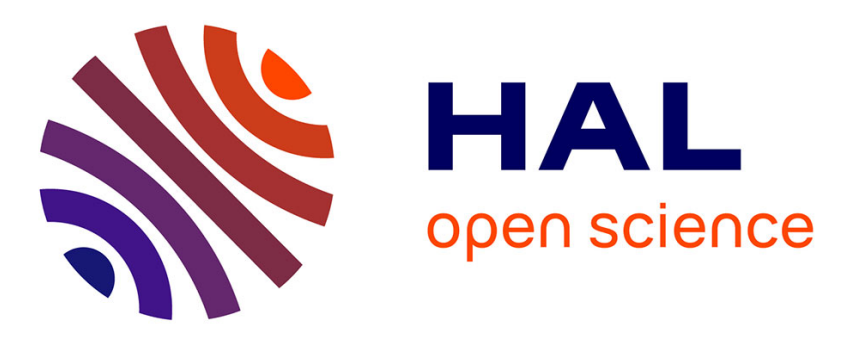

\title{
Santé orale et alimentation chez les personnes âgées : une adaptation multifactorielle
}

Ségolène Fleury, Mathilde Vandenberghe-Descamps, Chantal Septier, Gilles Feron, Hélène Labouré, Claire Sulmont-Rossé

\section{- To cite this version:}

Ségolène Fleury, Mathilde Vandenberghe-Descamps, Chantal Septier, Gilles Feron, Hélène Labouré, et al.. Santé orale et alimentation chez les personnes âgées: une adaptation multifactorielle. JFN 2017, Journées Francophones de Nutrition, Dec 2017, Nantes, France. 1 p., 2017. hal-02786245

\section{HAL Id: hal-02786245 \\ https://hal.inrae.fr/hal-02786245}

Submitted on 4 Jun 2020

HAL is a multi-disciplinary open access archive for the deposit and dissemination of scientific research documents, whether they are published or not. The documents may come from teaching and research institutions in France or abroad, or from public or private research centers.
L'archive ouverte pluridisciplinaire HAL, est destinée au dépôt et à la diffusion de documents scientifiques de niveau recherche, publiés ou non, émanant des établissements d'enseignement et de recherche français ou étrangers, des laboratoires publics ou privés. 


\section{Santé orale et alimentation chez les personnes âgées :}

\section{une adaptation multifactorielle}

S. Fleury ${ }^{1}$, M. Vandenberghe-Descamps ${ }^{1}$, C. Septier ${ }^{1}$, G.Feron $^{1}$, H. Labouré ${ }^{1}$, C. Sulmont-Rossé $^{1}$

${ }^{1}$ Centre des Sciences du Goût et de l'Alimentation, AgroSup Dijon, CNRS, INRA, Univ. Bourgogne Franche-Comté, Dijon Cedex
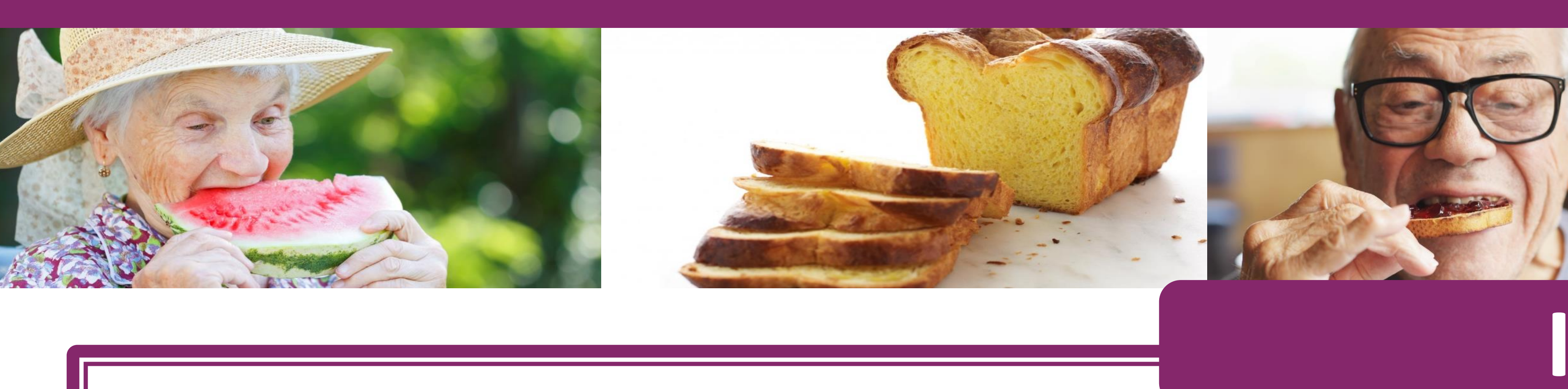

\section{Introduction}

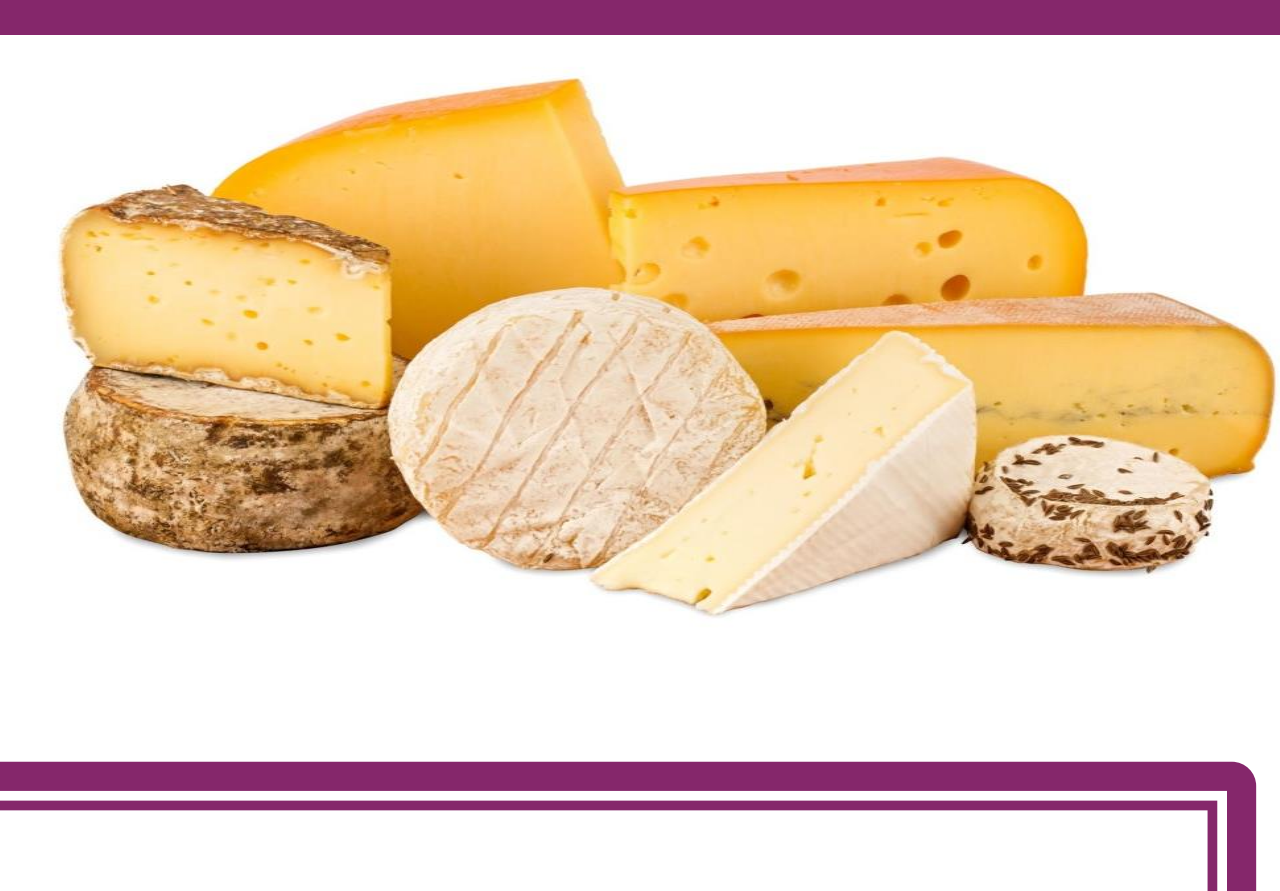

Le vieillissement peut s'accompagner de changements dans la sphère orale tels que la diminution de l'efficacité masticatoire ou encore la dégradation quantitative et qualitative de la salive. Ces changements peuvent diminuer la capacité des personnes âgées à dégrader l'aliment, et éventuellement à des comportements d'évitement. L'objectif est d'étudier l'impact de la dentition et des flux salivaires sur les consommations alimentaires des personnes âgées.

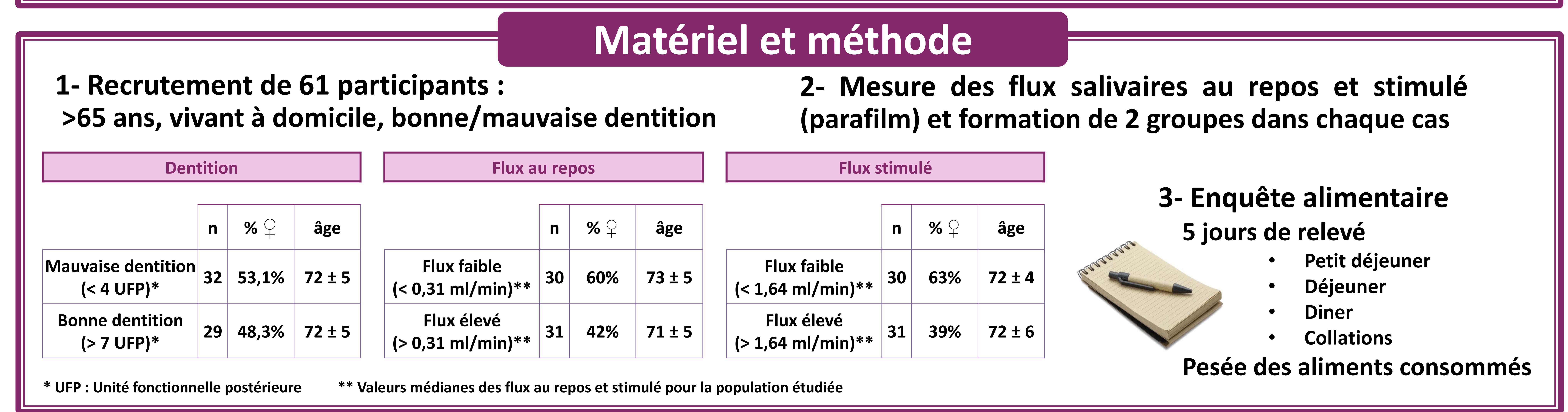

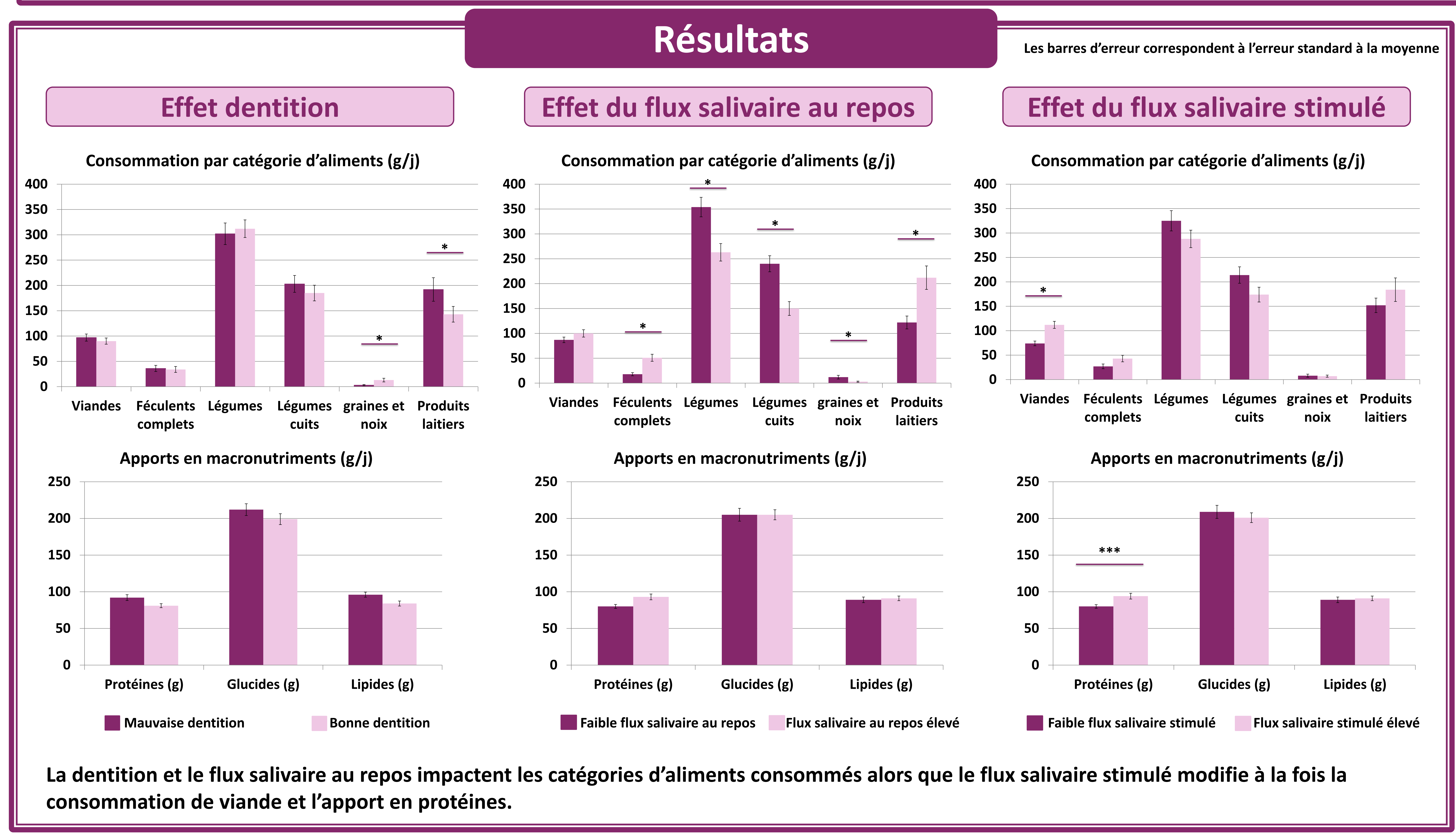

\section{Conclusion}

L'enquête alimentaire montre que la dentition et les flux salivaires affectent différemment la prise alimentaire du sujet âgé en la modifiant d'un point de vue qualitatif et/ou quantitatif. Si l'impact de la dentition sur l'alimentation a été largement exploré, cette étude met en avant pour la première fois l'importance de la salivation dans l'acte alimentaire. Ces résultats permettront de développer des aliments adaptés aux troubles et aux changements oraux qui surviennent avec l'âge.

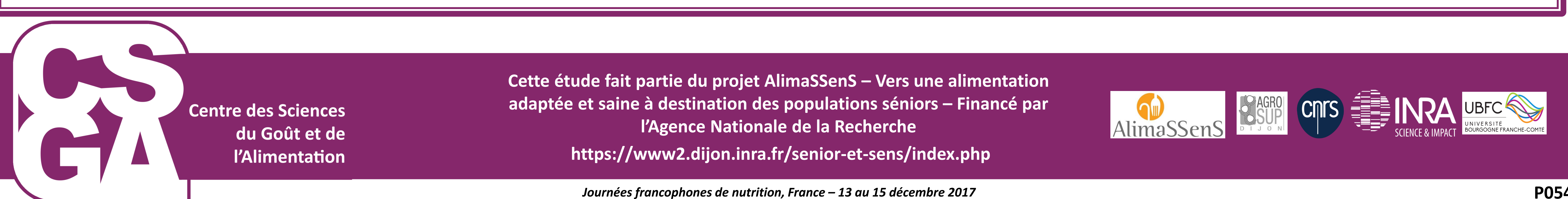

